\title{
The time course of fear incubation following single-trial passive-avoidance training
}

\author{
JOSEPH D. ALLEN and JUDSON C. MITCHAM \\ University of Georgia, Athens, Ga. 30601
}

The time course of fear incubation was obtained by measuring single-trial passive-avoidance latencies in an alley following postshock training delays of $1,2,4,6$, 12,24 , or $60 \mathrm{~h}$ for different groups of rats. The function relating mean running latency and postshock delay interval was increasing and negatively accelerated, reaching a maximum at $24 \mathrm{~h}$. Some problems with relating the different incubation functions derived by a single-trial passive-avoidance procedure vs an active-avoidance procedure are discussed.

The systematic increase in fear over time since original conditioning, as reflected by various response measures, has been termed the incubation effect. Several studies have investigated the incubation effect by using a single-trial passive-avoidance training procedure. The $S s$ are first trained to (1) enter a goal compartment for food (Miller, 1961), (2) mount a lever for water (Pinel \& Cooper, 1966a b), or (3) are stabilized on stepdown latencies from a platform to a grid floor (Riddell \& Herman, 1968). The "goal response" is then paired with unavoidable shock, and the $\mathrm{Ss}$ are tested for passive avoidance following varying postshock delay intervals. By combining the results of these studies it may be inferred that fear (latency to complete the goal response) increases reliably and monotonically over a 24-h postshock retention interval. However, the time course of fear incubation has not yet been adequately specified due to (1) an insufficient sampling of retention intervals, especially intervals longer than $1 \mathrm{~h}$ postshock, (2) failure either to report or to use deprivation control procedures for the different test-interval groups, and (3) frequent use of a short response-latency criterion (usually $5 \mathrm{~min}$ ) during the test that may have imposed a ceiling on the passive-avoidance measure. The present study attempted to rectify these problems and to describe more systematically the incubation of fear for retention intervals longer than $1 \mathrm{~h}$ postshock.

SUBJECTS AND APPARATUS

The 35 male Holtzman rats were approximately 110 days old and were reduced to $85 \%$ of their free-feeding weights 5 days prior to and for the duration of the experiment. Stabilized daily food intake (Purina meal) ranged between 8 to $12 \mathrm{~g}$ over individual Ss, and free access to water was provided in the home cage.

The Ss were run in a straight alley that

Fig. 1. Mean response latencies as a function of postshock delay interval. was $10.5 \mathrm{~cm}$ wide $\times 9.0 \mathrm{~cm}$ high (inside dimensions); was subdivided into $30.5-\mathrm{cm}$ starting, $70.2-\mathrm{cm}$ running, and $30.5-\mathrm{cm}$ goal compartments by two horizontally sliding retrace doors; and was painted flat black throughout. The flooring in the starting and running compartments was wood. The goal compartment contained a grid of 18 steel rods, $4 \mathrm{~mm}$ in diam and spaced $1.5 \mathrm{~cm}$ apart center to center. Unscrambled $0.4-\mathrm{mA}$ shock could be delivered to the grids in alternating polarity by a Lehigh Valley Model 1531 constant-current shocker. Running latencies were manually timed to $0.1 \mathrm{sec}$ with a stopwatch.

\section{PROCEDURE}

On Days 1.5, Ss were trained to run the alley in seven arbitrarily composed squads of five Ss each. They received 25 training trials at a rate of 5 trials per day. Each trial commenced by placing $S$ in the starting chamber and allowing $3 \mathrm{sec}$ of maintained orientation toward the start door. The stopwatch was started simultaneously with the opening of the door and was stopped when S's nose was over the food cup. After consuming the $45-\mathrm{mg}$ Noyes pellet, $\mathrm{S}$ was removed to a carrying cage for an Directly following each day's session, Ss received their daily adjusted food ration (8-12 g) in their home cages. Following the 25 th trial, the Ss were redistributed into seven equal groups that were matched on mean running latency over the last 15 training trials.

Passive-avoidance training was conducted on Day 6. Upon receipt of the pellet on the first trial, each $S$ was given a burst of three $0.4-\mathrm{mA}$ shocks during a $2-\mathrm{sec}$ interval. Each $\mathrm{S}$ was immediately given a second trial and those that left the starting compartment before a criterion $30-\mathrm{sec}$ interval received a second series of shocks in the goal compartment. Ss that met the criterion were removed from the starting compartment and were returned to their home cages.

The groups were assigned randomly to the following seven postshock delay intervals: $1,2,4,6,12,24$, or $60 \mathrm{~h}$. During the delay interval, Ss were housed in their home cages and were fed an amount of meal calculated to bring them to their $85 \%$ running weights by the start of the postshock retention trial. Meal sizes were calculated from an unpublished chart relating the evacuation rate of food in a rat's stomach over a $24-\mathrm{h}$ period obtained previously in" this laboratory. At the end of its postshock retention interval, each group was given one passive-avoidance trial in the alley that was identical to a training trial except that a 10-min criterion was imposed upon the running latency. The four Ss that exceeded this criterion (one $S$ in the $12-\mathrm{h}$ group, two Ss in the 24-h group, and one $S$ in the 60 -h group) were assigned a running latency of $600 \mathrm{sec}$.

\section{RESULTS}

The Ss' mean running latency stabilized at $2.4 \mathrm{sec}(\mathrm{SD}=1.4 \mathrm{sec})$ over the last 15 training trials. The effect of the postshock delay intervals on group mean running latencies is shown in Fig. 1. Beginning with a $48-\mathrm{sec}$ latency at $1 \mathrm{~h}$, mean running

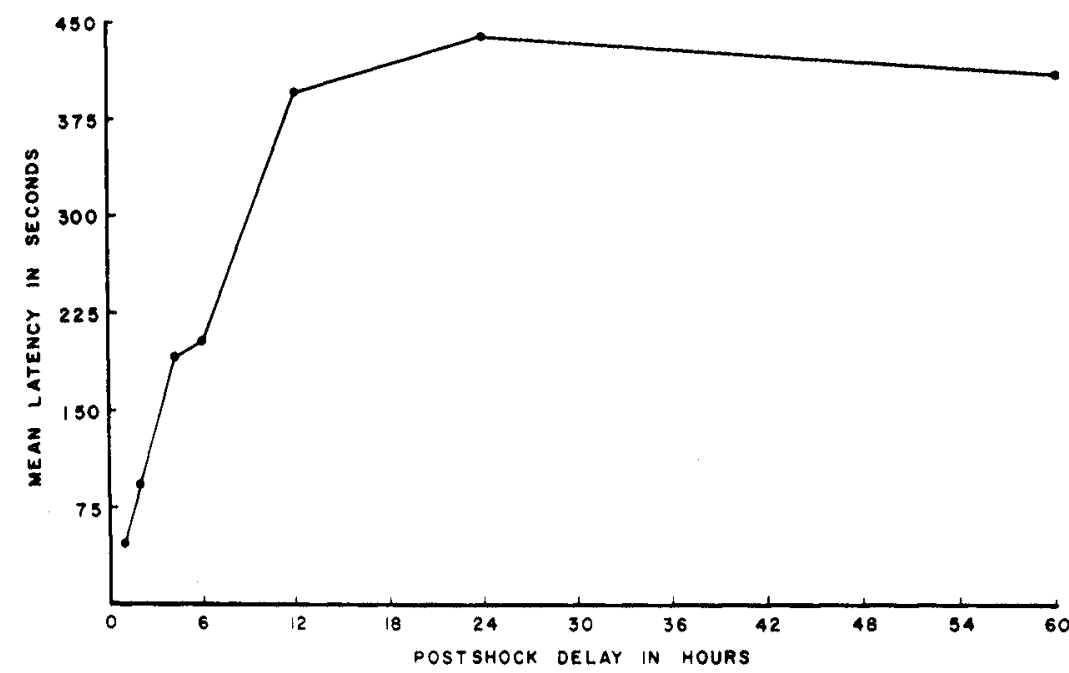

Psychon. Sci., 1970, Vol. 20 (3) 
Table 1

Calculated Postshock Meal Sizes, Mean Running Weights, Mean Test Weights, and Mean Percentage Weight Differences

$$
\left[\frac{\text { Postshock Weight }- \text { Run Weight }}{\text { Run Weight }} \times 100\right]
$$

for the Seven Postshock Interval Groups

\begin{tabular}{ccccr}
\hline $\begin{array}{c}\text { Post- } \\
\text { Shock }\end{array}$ & $\begin{array}{c}\text { Postshock } \\
\text { Meal } \\
\text { Group }\end{array}$ & $\begin{array}{c}\text { Mean } \\
\text { Running } \\
\text { Weight }\end{array}$ & $\begin{array}{c}\text { Mean } \\
\text { Test } \\
\text { Weight }\end{array}$ & $\begin{array}{r}\text { \% Weight } \\
\text { Diffe- } \\
\text { rence }\end{array}$ \\
\hline 1 & 2.6 & 317.4 & 316.8 & -.18 \\
2 & 2.0 & 311.0 & 310.4 & -.19 \\
4 & 6.2 & 317.4 & 313.6 & -1.19 \\
6 & 5.1 & 298.0 & 297.4 & -.20 \\
12 & 9.4 & 314.2 & 313.6 & -.19 \\
24 & 12.0 & 326.0 & 328.8 & .85 \\
60 & $9.4^{*}$ & 337.8 & 337.6 & -.05 \\
\hline
\end{tabular}

* Ss fed $12 \mathrm{~g}$ for first 2 postshock days. then $9.4 \mathrm{~g}$ on third dav.

latency rises sharply to $12 \mathrm{~h}$ and then more slowly to a peak latency of $438 \mathrm{sec}$ at $24 \mathrm{~h}$. Mean latency then drops slightly to $401 \mathrm{sec}$ at $60 \mathrm{~h}$ postshock. Multiple between-group comparisons were performed on the group mean running latencies with a Duncan multiple range test $(p=.05$ level set) after a univariate analysis of variance among groups was significant $(F=3.73, \mathrm{df}=6 / 28$, $\mathrm{p}=.05)$. The $1-, 2-$, and $4-\mathrm{h}$ groups do not differ from each other, but all differ significantly from the $12-, 24-$, and 60 -h groups which do not differ from each other. The 6-h group differs only with the 24-h group.

Table 1 presents the mean running weights and calculated postshock meal sizes for each group, and reveals the adequacy with which the calculated meal sizes insured stabilized postshock test weights. Mean running weights did not vary systematically over the postshock interval groups, and the percentage weight difference between mean running weight and mean test weight was usually well within $1 \%$ of the mean running weight except for the 4-h group, whose mean test weight was reduced by $1.19 \%$.

$$
\text { DISCUSSION }
$$

Besides confirming the monotonic and increasing functions reported by previous single-trial passive avoidance studies, our data show that fear incubates as a negatively accelerated function of time since shock and reaches a maximum (and probably an asymptote) at $24 \mathrm{~h}$ postshock. The difference between the average training and testing body weights was negligible for all groups, and the $10-\mathrm{min}$ test latency criterion permitted a sensitive assessment of our response measure.

Our data do not conform to those of other investigations of the incubation effect which have used the retention and retraining of an incompletely learned avoidance response as a measure of fear. With the exception of Anderson et al (1966), those studies have typically reported a progressive decrement in active-avoidance performance at successive posttraining intervals up to 1 or $4 \mathrm{~h}$ followed by a reversal and progressive performance recovery at longer delay intervals (Kamin, 1957, 1963; Denny \& Ditchman, 1962; Brush, Meyer, \& Palmer, 1963). Our results offer no support for a similar nonmonotonic function over a $24-\mathrm{h}$ retention interval, which suggests that the single-trial passive-avoidance task engenders and records processes that are different from those that have been theorized to produce the "Kamin effect."

At present, the different incubation functions resulting from the typical activevs passive-avoidance tasks do not seem to be attributable to the type of response measured during the test. Both Tarpy (1966) and McMichael (1966) have reproduced the Kamin effect by superimposing stimuli, associated with shock in active-avoidance training, upon an appetitively maintained lever-press response and then measuring the degree of conditioned suppression. On the other hand, other training and testing differences do seem to be clearly implicated. First, the active-avoidance procedure involves the use of many more shock presentations (25 to 40 shocks) than does the usual passive-avoidance procedure (1 or 2 shocks). Number of training shocks has been shown to interact markedly with performance in a subsequent test situation (Wagman \& Allen, 1964). Secondly, the active avoidance designs typically report the mean performance over a lengthy test session (25 to 40 trials), presumably because the initial avoidance performance is confounded with a warm-up effect (Kamin, 1963). A one-trial test is used with the passive avoidance designs, and warm-up following even long intertrial intervals, at least in alley running performance, is negligible (Ehrenfreund \& Allen, 1964). One interesting finding is that, when the initial test trial performance in an active-avoidance task is reported, a monotonic decrease in active-avoidance performance over a 24 -h delay interval has been found (Kamin, 1963; Brush, Meyer, \& Palmer, 1963). Lastly, the active-avoidance designs have typically compounded fear of situational-apparatus cues with fear of a discrete $\mathrm{CS}$ during the test situation, whereas single-trial passive-avoidance designs have relied on situational cues alone. Attempts to partially separate the effects of these two cue sources in active-avoidance designs have suggested that fear of CS cues alone incubates to a maximum in $4 \mathrm{~h}$ in a CER test (Tarpy, 1966), whereas fear of predominantly apparatus cues incubates monotonically over a 24-h delay interval when the acquisition of an active avoidance response is measured (McAllister \& McAllister. 1963. 1965).

No fear-incubation theory with adequate generality may be proposed until the complex procedural interfaces that apparently separate the data generated by these different approaches are parametrically investigated and resolved. Some of the most glaring procedural differences between the active- and passive-avoidance tasks have been enumerated here.

\section{REFERENCES}

A N DER SON, D. C., JOHNSON. L., SCHWENDIMAN, G., \& DLNFORD. G. Retention of an incompletely leamed avoidance response: Some problems with replication. Psychonomic Science, 1966, 6, 23-24.

BRUSH, F. R., MEYER, J. S., \& PALMER, M. E. Effects of kind of prior training and intersession interval upon subsequent avoidance learning. Journal of Comparative \& Physiological Psychology, 1963, 56, 539-545. DENNY, M. R., \& DITCHMAN, R. E. The locus of the maximal "Kamin effect" in rats. Journal of Comparative \& Physiological Psychology, 1962, 55, 1069-1070.

EHRENFREUND, D., \& ALlen, J. Perfect retention of an instrumental response. Psychonomic Science, 1964, 1, 347-348.

KAMIN, L. J. Retention of an incompletely learned avoidance response: Some further analyses. Journal of Comparative \& Physiological Psychology, 1963. 56, 713-718.

KAMIN, L. J. The retention of an incompletely learned avoidance response. Journal of Comparative \& Physiological Psychology, $1957,50,457-460$.

MCALLISTER, W. R., \& McALLISTER, D. E. Increase over time in the stimulus generalization of acquired fear. Journal of Experimental Psychology, 1963, 65, 576-582.

MCALLISTER, W. R., \& McAlLISTER, D. E. Variables influencing the conditioning and the measurement of acquired fear. In W. Prokasy (Ed.). Classical conditioning: $A$ symposium. New York: Appleton-Century, 1965. Pp. 172.191.

MCMICHAEL, J. S. Incubation of anxiety and instrumental behavior. Journal of Comparative \& Physiological Psychology, 1966, 61, 208-211.

MILLER, N. E. Some recent studies of conflict behavior and drugs. American Psychologist, $1961,16,12-24$.

PINEL, J. P. J., \& COOPER, R. M. Incubation and its implications for the interpretation of the ECS gradient effect. Psychonomic Science, 1966a, 63, 123-124.

PINEL, J. P. J., \& COOPER, R. M. The relationship between incubation and ECS gradient effects. Psychonomic Science, 1966, 6, 125-126.

RIDDELL, W. I., \& HERMAN, T. Incubation in one-trial passive avoidance learning: $A$ cautionary note. Psychonomic Science, 1968 , $12,335-336$

TARPY, R. M. Incubation of anxiety as measured by response suppression. Psychonomic Science, 1966, 4, 189-190.

WAGMAN, W., \& ALLEN, J. D. The uevelopment of a conditioned positive reinforcer based upon the termination of shock. Psychonomic Science, 1964, 1, 363-364. 